\title{
Analysis of Measured Drop Size Spectra over Land and Sea
}

\author{
Karl Bumke ${ }^{1}$ and Jörg Seltmann ${ }^{2}$ \\ ${ }^{1}$ GEOMAR|Helmholtz-Zentrum für Ozeanforschung Kiel, Maritime Meteorologie, Düsternbrooker Weg 20, 24105 Kiel, Germany \\ ${ }^{2}$ Deutscher Wetterdienst, Albin-Schwaiger-Weg 10, 82383 Hohenpeißenberg, Germany
}

Correspondence should be addressed to Karl Bumke, kbumke@geomar.de

Received 17 August 2011; Accepted 20 September 2011

Academic Editors: U. Kulshrestha, F. Tao, and D.-Y. Wang

Copyright ( 2012 K. Bumke and J. Seltmann. This is an open access article distributed under the Creative Commons Attribution License, which permits unrestricted use, distribution, and reproduction in any medium, provided the original work is properly cited.

Drop size spectra were measured by using an optical disdrometer of type ODM 470 at different locations. They were subdivided in to four data sets: measurements over land, in coastal areas, over semienclosed seas, and over the open sea. Based on 1-minute measurement intervals, no differences were found in drop size spectra between continental and maritime areas. An exponential model with a rain rate depending on interception number and prefactor in the exponent fits well the spectra, and maximum drop sizes depend strongly on estimated rain rates. In contrast to other investigations, there are no significant differences between spectra of convective and stratiform rain based on 1-minute measurement intervals. However, spectra integrated over 10 minutes show the expected differences.

\section{Introduction}

A detailed knowledge of rain drop size densities is an essential presumption with respect to remote sensing of precipitation. Recent research reveals that rain drop size densities can be described either by an exponential distribution (e.g., Marshall and Palmer [1]), a gamma distribution (e.g., Ulbrich and Atlas [2]), or a Weibull distribution (e.g., Sekine et al. [3]).

Drop size densities also are influenced by the precipitation formation processes in clouds. Since maritime and continental aerosols are significantly different leading to differences in cloud drop size spectra, one may assume that maritime and continental rain drop size densities (DSDs) are different, too. In fact, only little is known about differences in rain drop size spectra between land and sea due to a lack of suitable data over the sea. To fill in this gap, measurements were performed during the recent 10 years at different locations in Germany, over the Baltic Sea, the North Sea, and Atlantic, Indic, and Pacific Oceans.

Measurements were conducted by using an optical disdrometer [4], which has been specially designed to perform precipitation measurements on moving ships.

Drop size densities may also differ for prevailing stratiform or convective precipitation as was shown, for example, by Uijlenhoet et al. [5]. For subsets of the existing data, weather radar information is available to decide whether precipitation is of convective or stratiform nature. This enables to investigate differences in drop size spectra of convective and stratiform precipitation.

\section{Optical Disdrometer}

Measurements of drop size spectra on moving ships are difficult to perform. To meet requirements such as high sea states, high relative wind speeds, and irregular flow patterns around the ship's superstructure, an optical disdrometer was developed at the IFM-GEOMAR [6]. Today, this instrument is called ODM 470 and is produced by Eigenbrodt Environmental Measurements, Germany (Figure 1).

The principle of the disdrometer is light extinction of an infrared light-emitting diode at $880 \mathrm{~nm}$ wavelength caused by hydrometeors passing through a cylindrical optical sensitive volume of $120 \mathrm{~mm}$ length and $22 \mathrm{~mm}$ diameter, which is kept perpendicular to the local wind with the aid of a wind vane. The cylindrical form of the volume itself ensures the measurements to be independent of the incident angle of hydrometeors. The magnitude of the electronic signal caused by a rain drop is proportional to its cross-sectional area; its length gives the residence time of a rain drop in the sensitive volume depending on the size-dependent falling velocity of 


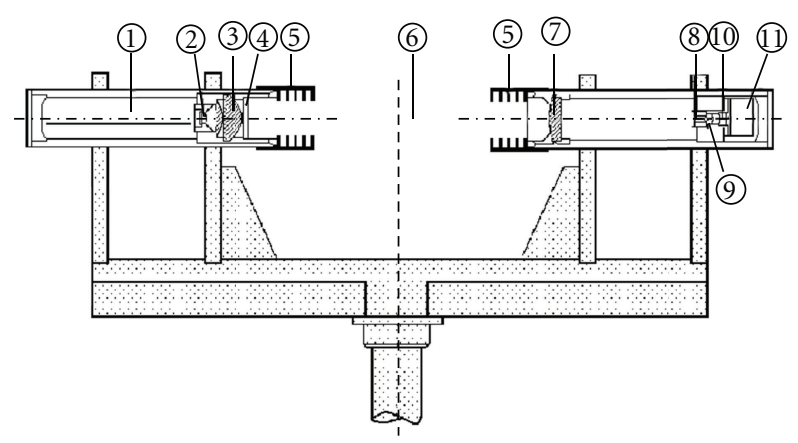

FIGURE 1: Sketch of the optical disdrometer ODM 470. From left to right: electronics (1), light-emitting diode (2), lens system (3), window (4), baffles (5), sensitive volume (6), achromatic collector lens (7), optical blend (8), ocular (9), photo diode (10), and electronic compartment (11).

the drop and local wind speed. Local relative wind speed is measured by a cup anemometer. For the falling velocity $V_{\text {fall }}$, more accurate the terminal falling velocity, an approach of Atlas et al. [7] is used as follows:

$$
V_{\text {fall }}=9.65-10.3 \cdot \exp (-0.6 \cdot d),
$$

where $d$ is the drop diameter in millimetres and $V_{\text {fall }}$ in $\mathrm{ms}^{-1}$.

The disdrometer allows to measure drops from about 0.4 to $6.4 \mathrm{~mm}$ diameter portioned in equally spaced size bins of $0.0496 \mathrm{~mm}$. After correcting the measurements for coincidence effects caused by multiple hydrometeors within the sensitive volume at the same time and for edge effects, precipitation rates $R$ were calculated according to Clemens [8] to be

$$
R=\sum_{i=1}^{128} \frac{N_{i}}{A \cdot T_{0} \cdot \sqrt{U^{2}+V_{\text {fall }}^{2}\left(d_{i}\right)}} \cdot V_{\text {drop }} \cdot \rho \cdot V_{\text {fall }}\left(d_{i}\right),
$$

where $i$ indicates the $i$ th size bin, $d_{i}$ is the drop diameter in $\mathrm{m}, U$ is the wind speed relative to the disdrometer in $\mathrm{ms}^{-1}$, $V_{\text {drop }}$ is the drop volume in $\mathrm{m}^{3}, V_{\text {fall }}\left(d_{i}\right)$ is the terminal falling velocity according to (1) in $\mathrm{ms}^{-1}, A=0.12 \mathrm{~m} * 0.022 \mathrm{~m}$ is the cross-section of the optical sensitive volume, $T_{0}$ is the interval of measurements in s, $\rho$ is the density of water in $\mathrm{kg} \mathrm{m}^{-3}$, and $N_{i}$ is the number of rain drops counted in each size class. The denominator is the volume,

$$
V\left(d_{i}\right)=A \cdot T_{0} \cdot \sqrt{U^{2}+V_{\text {fall }}^{2}\left(d_{i}\right)}
$$

scanned by the optical disdrometer.

\section{Data}

Measurements took place at a number of locations between 1997 and 2007. These were two stations on main land: Achern in Southwest Germany $\left(48.6^{\circ} \mathrm{N}, 8.1^{\circ} \mathrm{E}\right)$ and Berlin $\left(52.5^{\circ} \mathrm{N}, 13.4^{\circ} \mathrm{E}\right)$. The minimum distances to the coast are about 600 and $200 \mathrm{~km}$; three coastal stations are Zingst in Northeast Germany $\left(54.4^{\circ} \mathrm{N}, 12.6^{\circ} \mathrm{E}\right)$, Westermarkelsdorf

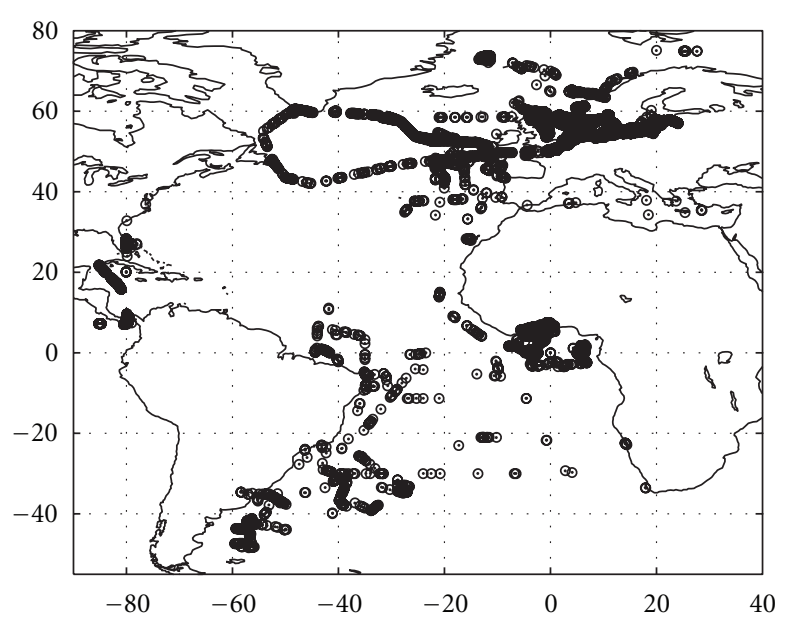

Figure 2: Positions of R/V Alkor (Baltic Sea and North Sea), R/V Meteor (Atlantic and Indian Ocean), and R/V Ron Brown (Atlantic and Pacific Oceans East and West of Central America). Positions are restricted to those where rain has been measured.

$\left(54.5^{\circ} \mathrm{N}, 11.1^{\circ} \mathrm{E}\right)$ and Kiel $\left(54.3^{\circ} \mathrm{N}, 10.1^{\circ} \mathrm{E}\right)$ in Northern Germany, and all stations are located along the coast of the Baltic Sea; two stations in areas of the semienclosed North Sea and Baltic Sea: Helgoland $\left(54.2^{\circ} \mathrm{N}, 7.9^{\circ} \mathrm{E}\right)$ which is a very small island in the German Bight about $60 \mathrm{~km}$ away from the German coast and R/V Alkor cruising in the Baltic and North Sea; two stations over the open sea, the USA. R/V Ron Brown and the German R/V Meteor operating in the Atlantic Ocean and tropical Pacific Ocean. Locations with rain measurements of all three research vessels are depicted in Figure 2. Heights of measurements vary between about $10 \mathrm{~m}$ (Westermarkelsdorf) to $150 \mathrm{~m}$ (Achern) above sea level.

Temporal resolution of measurements is generally 1 minute. To exclude measurements of solid precipitation, simultaneously measuring unheated ship rain gauges were used as an additional source of information except for measurements on board of R/V Meteor. Here, we used available synoptic information.

Especially over land measurements may be disturbed temporally by spider nets; such measurements were removed from spectral information.

\section{Results}

4.1. Influence of Wind Speed on Measurements. The capability of an optical disdrometer to measure drop size spectra may be limited due to the volume $V$ of air scanned by an optical disdrometer at a certain drop size (2), which is proportional to the cross-section of the optical sensitive volume and depends strongly on the local wind speed and, according to (1), the terminal falling velocity or the drop size itself. Thus, ideally estimated drop size spectra should not be a function of local wind speed. Although model simulations of disdrometer measurements showed that the disdrometer performs well for drops of more than $0.4 \mathrm{~mm}$ in diameter [4], this was checked for measurements on board of the R/V Alkor, which comprises a sufficient number of precipitation 


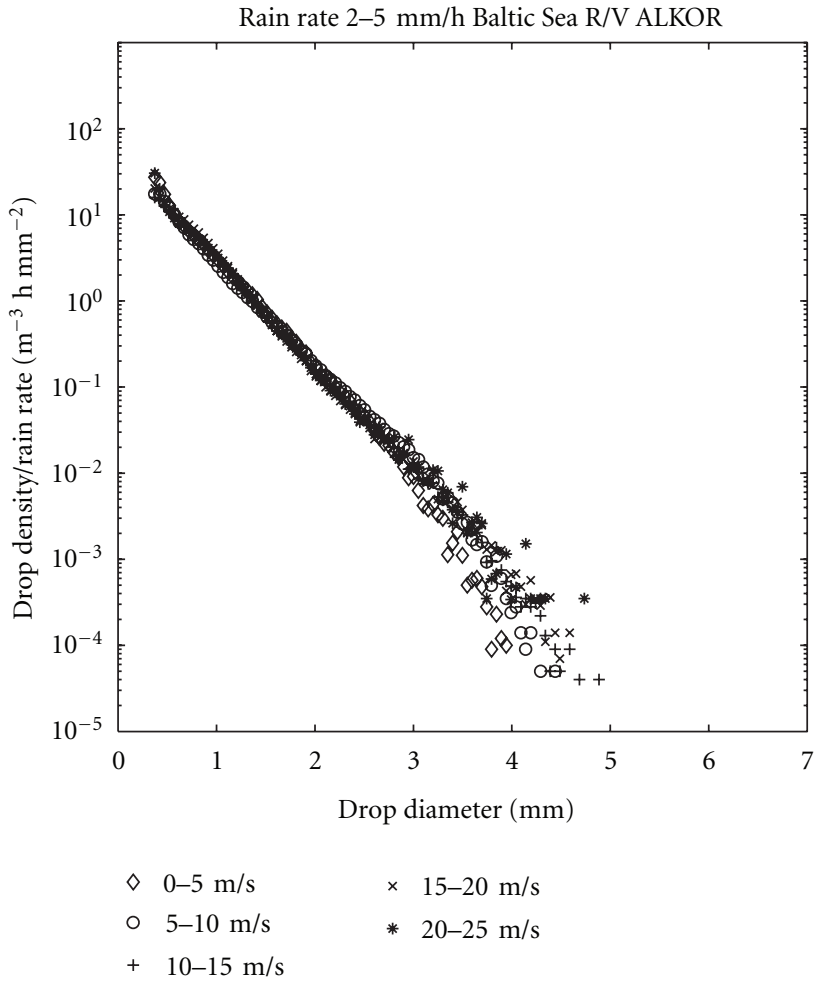

(a)

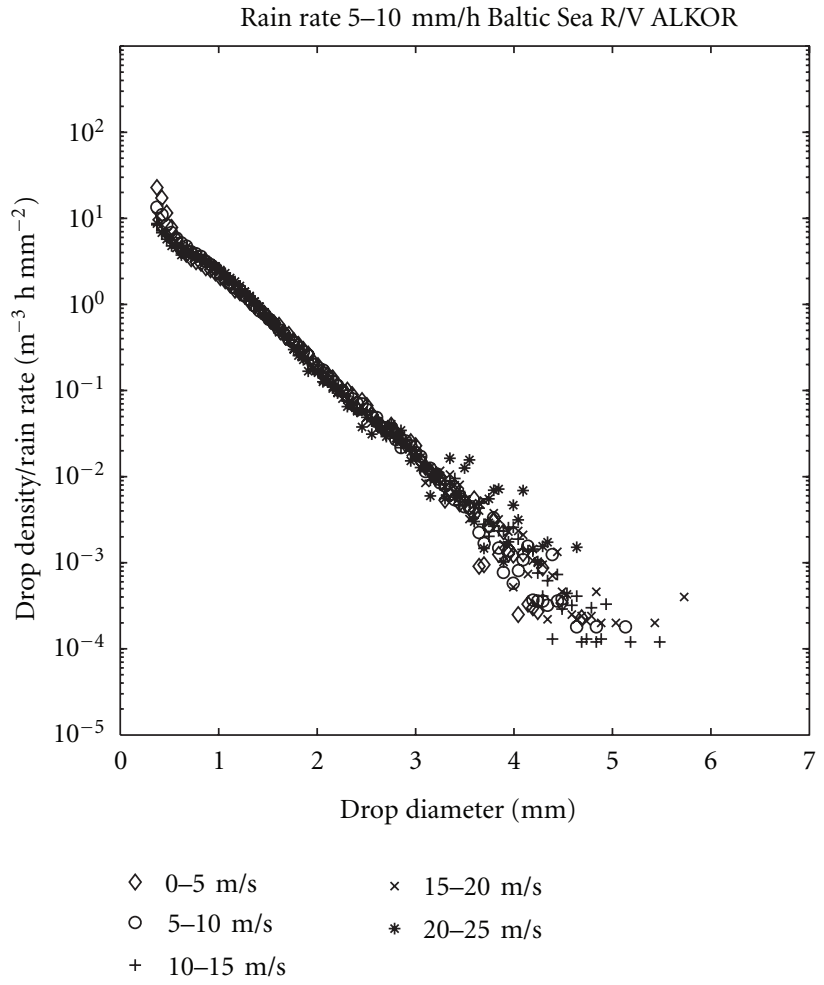

(b)

FIgURE 3: Drop size densities for a rain rate of 2 to $5 \mathrm{~mm} \mathrm{~h}^{-1}$ (a) and 5 to $10 \mathrm{~mm} \mathrm{~h}^{-1}$ (b) averaged over different wind speed intervals. Measurements took place on R/V Alkor, and drop size densities are normalized with rain rate and width of the size intervals ( $0.0496 \mathrm{~mm})$ of the optical disdrometer.

measurements under wind speeds to $25 \mathrm{~ms}^{-1}$. An example is given in Figure 3. It turned out that there are no significant differences between measured drop size spectra at a given rain rate under varying wind speeds checked by a Kolmogoroff Smirnoff test at the 0.95 significance level. Thus, it can be concluded that drop size densities are well represented by the measurements even under conditions of low wind speeds, when the scanned volume of air is a minimum especially for small drops. Therefore, in the following, no further discrimination of rain events was made according to wind speed.

Another problem of disdrometers, especially of impact disdrometers like the Joss Waldvogel disdrometer, is to underestimate the occurrence of small drops [9], which have to be corrected, for example, by empirical formulas based on the number of counted drops [10]. A comparison took place in Westermarkelsdorf on the Island of Fehmarn in the Baltic Sea between the optical disdrometer, a Joss-Waldvogel disdrometer (e.g., Joss and Waldvogel [11]), and a Micro Rain Radar [12]. Figure 4 shows a comparison between measured drop size densities at rain rates ranging from 0.5 to $4 \mathrm{~mm} \mathrm{~h}^{-1}$. There is a good agreement between the different instruments; deviations between the Joss-Waldvogel disdrometer and the other instruments at smallest drops are due to a known underestimation of the Joss-Waldvogel disdrometer for these drops (e.g., Tokay et al. [9]) although the Joss-Waldvogel measurements were corrected according to $[10,13]$. Please note in this context that the instruments capability to resolve different drop sizes is limited due to measurement principles; while the drop size bins of the optical disdrometer are equally sized over the whole range, the resolutions of the JossWaldvogel disdrometer (20 size bins) and of the Micro Rain Radar (46 size bins) decrease with increasing drop diameter as it is indicated in Figure 4.

4.2. Performance of the Optical Disdrometer. Beside a number of tests during the development of the optical\% disdrometer $[4,6]$, the disdrometer was comprehensively tested against collecting rain gauges in the field. Rain measurements on the main building of the IFM-GEOMAR in Kiel from 1998 to 2003 showed that deviations between a Hellmann rain gauge and a ship rain gauge [14] are better than $2 \%$ in terms of accumulated rain sums at wind speeds of less than $5 \mathrm{~ms}^{-1}$. The chosen maximum wind speed ensures that flow distortion does not influence precipitation measurements of the Hellmann rain gauge (e.g., Sveruk [15]). The correlation coefficient is 0.99 based on 8-minute integration time of measurements. Comparisons between both instruments at higher wind speeds showed that the differences meet well the numbers given for flow distortion correction of the Hellmann rain gauge by Sveruk [15]. The disdrometer measurements itself were compared to ship rain gauge measurements on RV Alkor for the period of 19992005. At wind speeds below $8 \mathrm{~ms}^{-1}$, correlation coefficient is 


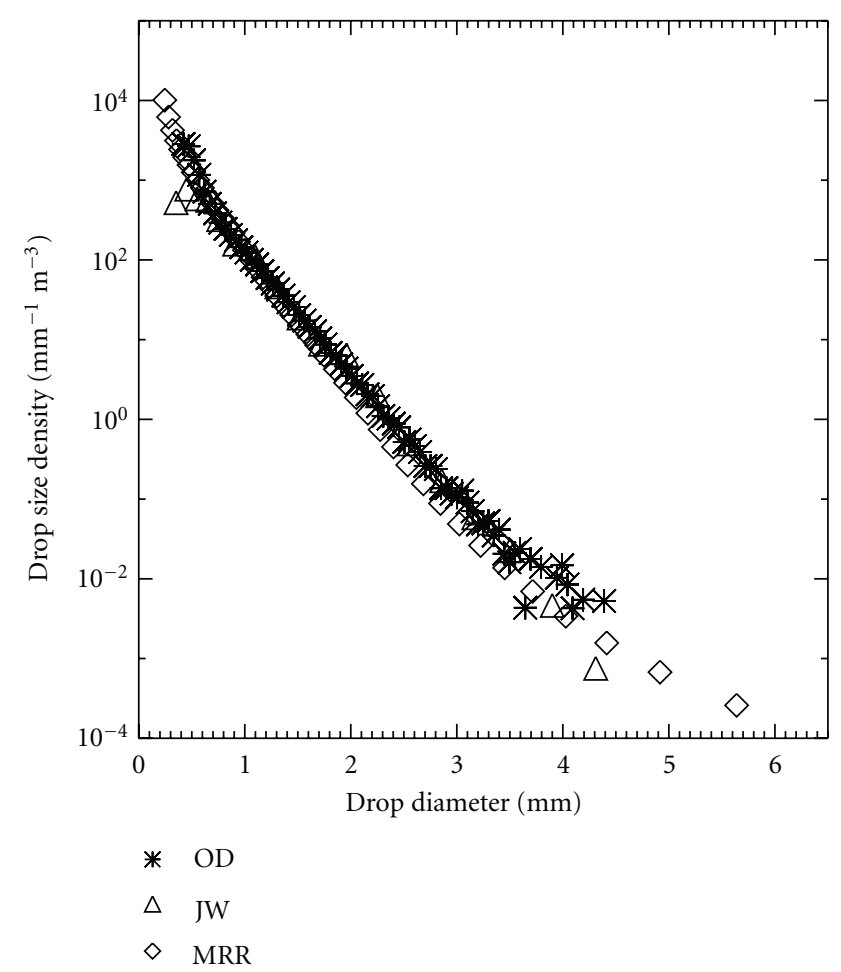

Figure 4: Drop size densities measured simultaneously by an optical disdrometer (OD), a Joss-Waldvogel disdrometer (JW), and a Micro Rain Radar (MRR) for rain rates, taken from the JossWaldvogel disdrometer, ranging from 0.5 to $4 \mathrm{~mm} \mathrm{~h}^{-1}$. Measur ements took place in Westermarkelsdorf on the island of Fehmarn in 2002 .

0.93 based on 1-minute integration time of measurements; using measurements under all wind speeds, the correlation coefficient is slightly reduced to 0.91 . The difference between both instruments is less than $3 \%$ in terms of accumulated rain. Correlation coefficients between an optical disdrometer and a ship rain gauge are generally smaller due to the principle of measurements. While the disdrometer gives instantaneous values, a ship rain gauge records the data with some delay. Further, the correlation is reduced by evaporation and wetting losses, which are typical errors of collecting instruments like the ship rain gauge.

4.3. Differences of Drop Size Densities Land Sea. As mentioned above drop size spectra might be influenced by the kind of aerosols serving as condensation nucleus. Therefore, it is necessary to estimate the origin of the air masses for the location of precipitation measurement. This could be done by making use of trajectories estimated from reanalysis data. Unfortunately, for example, Stohl [16] stated that trajectory errors of $20 \%$ of the distance travelled seem to be typical for trajectories computed from analysed fields; in data-scarce areas like oceans-errors may increase drastically. This is supported by a study of Engström and Magnusson [17], who have shown that due to uncertainties in the reanalysis data, the starting point of trajectories indicating the origin of air masses has mean uncertainties after 5 days of 300 to $900 \mathrm{~km}$ depending on the method and region. Since this does not allow any sufficient estimate of the origin of air masses, a simple approach has been used in the present study by classifying the measurements according to their location: land measurements, coastal measurements, measurements in areas of semienclosed seas, and open sea measurements. Results are given in Figure 5 as a function of rain rate, and numbers of observation are given in Table 1 . In general, differences in drop size spectra, normalized by precipitation rate, are small between different areas. Even at rain rates of 2 to $5 \mathrm{~mm} \mathrm{~h}^{-1}$, where differences in drop size spectra between coastal areas and open sea reach a maximum, a Kolmogoroff Smirnoff test does not show a significant difference between coastal and open sea spectra, tested at the 0.95 significance level. Normalizing the spectra according to a procedure as suggested by Testud et al. [18] gives comparable results. Thus, it can be stated that there are no systematic differences between drop size densities measured in maritime and continental environments. But several characteristics of the estimated drop size densities are obvious; an exponential model fits the data well; the intercept parameter seems to decrease slightly with precipitation rate; as well the regression coefficient as the maximum drop sizes depends on the measured precipitation rate itself.

To fit a model function to the estimated drop size spectra, measurements of all locations were averaged with respect to precipitation rate. Due to the probability distribution of precipitation rates, widths of averaging intervals range from $0.1 \mathrm{~mm} / \mathrm{h}$ for precipitation rates of less than $1 \mathrm{~mm} / \mathrm{h}$ up to $10 \mathrm{~mm} / \mathrm{h}$ for precipitation rates above $40 \mathrm{~mm} / \mathrm{h}$. The best fit to all measurements is given by

$$
\begin{aligned}
N(D)= & 6510 \mathrm{~m}^{-3} \mathrm{~mm}^{-1} \mathrm{~mm}^{0.14} \mathrm{~h}^{-0.14} \cdot R^{-0.14} \\
& \times \exp \left(-4.4 \mathrm{~mm}^{0.25} \mathrm{~h}^{-0.25} \cdot R^{-0.25} \cdot D \mathrm{~mm}^{-1}\right),
\end{aligned}
$$

(Figure 5) estimated by using the method of least squares. The precipitation-rate-dependent factor in the exponential is similar to that given by Marshall and Palmer [1]. The intercept parameter, in the original Marshall Palmer formulation not depending on the rain rate, is also of the same order. Drop size distributions agree well with the findings from Doelling et al. [19] based on long-term measurements at several locations in Germany using a Joss-Waldvogel disdrometer.

In contrast to some other publications (e.g., Mallet and Barthes [20]), a gamma model function did not give a better fit to the data.

4.4. Maximum Drop Size. The dependency of the maximum drop size $D_{\max }$ as a function of rain rate is shown in Figure 6 . Up to rain rates of about $25 \mathrm{~mm} \mathrm{~h}^{-1}$, it follows well the function

$$
D_{\max }(R)=3.7 \mathrm{~mm}+1.63 \mathrm{~mm} \cdot \log _{10}\left(R \mathrm{~mm}^{-1} \mathrm{~h}\right),
$$

for higher precipitation rates maximum drop size is constant, probably due to the fact that big drops became unstable and tend to fall in smaller drops [21]. The measured 


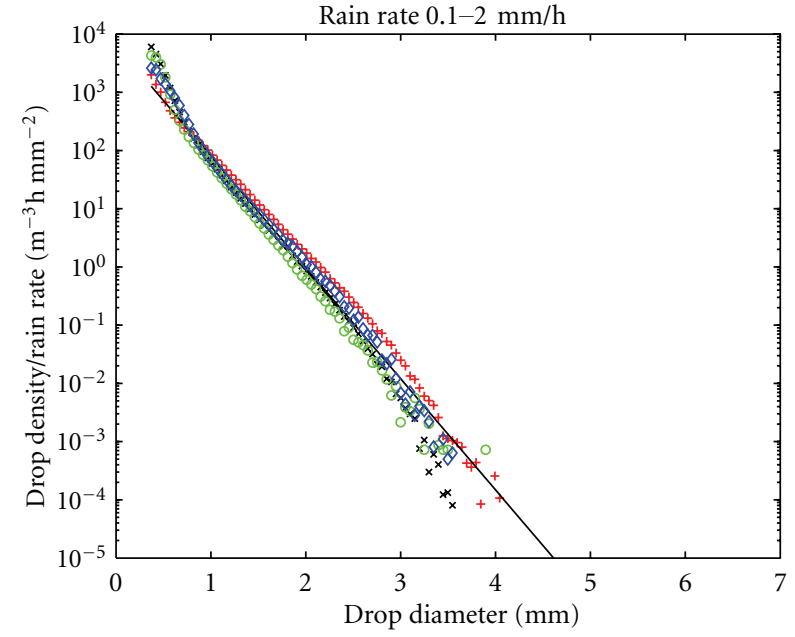

(a)

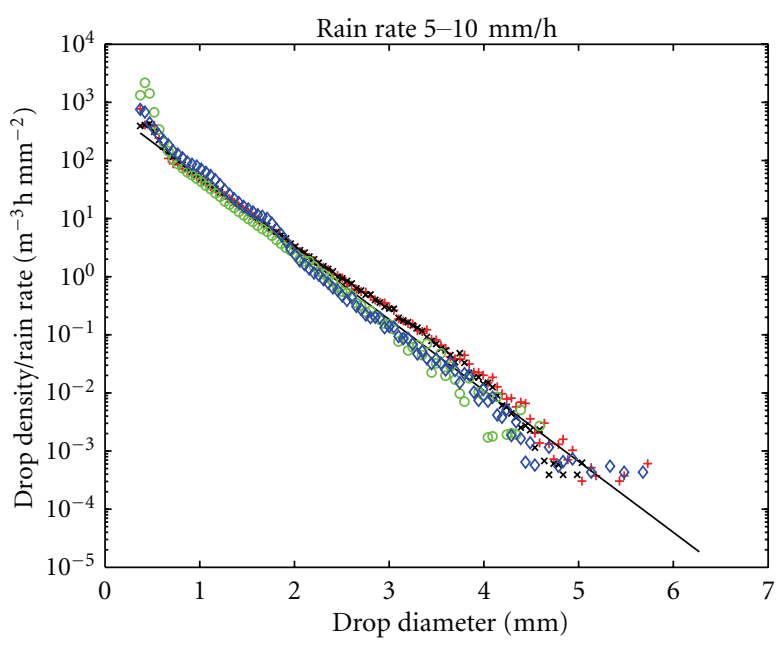

(c)

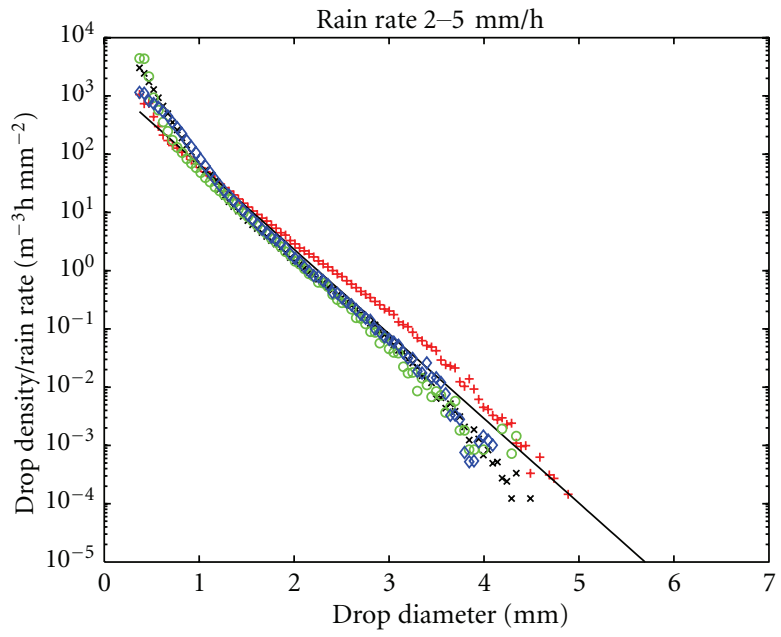

(b)

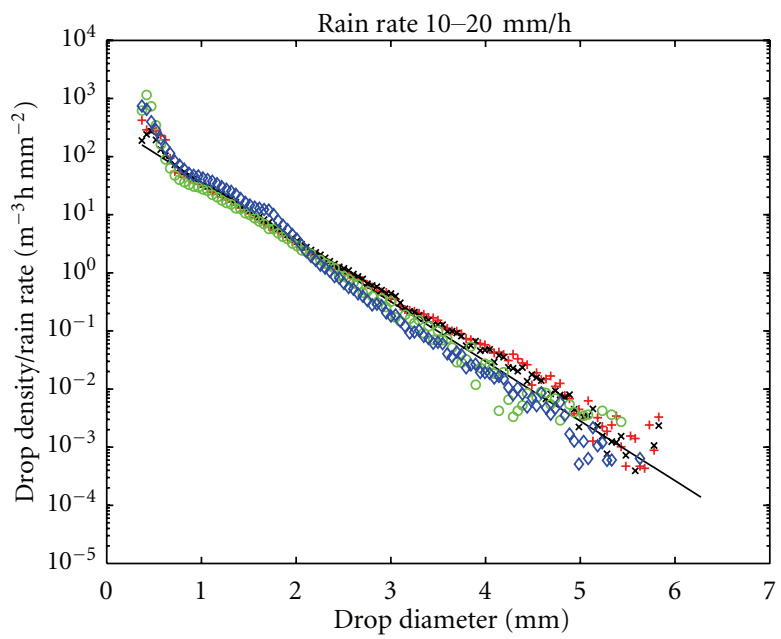

(d)

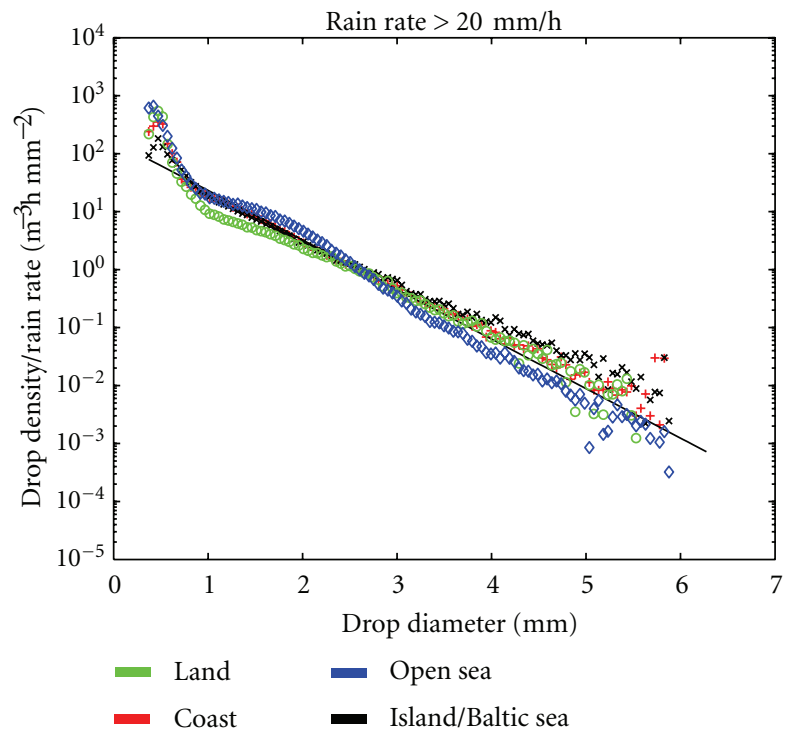

(e)

FIgURE 5: Drop size densities normalized with rain rate depicted for different precipitation rates $\left(0-2 \mathrm{~mm} \mathrm{~h}^{-1}\right.$ (a), 2-5 $\mathrm{mm} \mathrm{h}^{-1}(\mathrm{~b})$, 5-10 $\mathrm{mm} \mathrm{h}^{-1}(\mathrm{c}), 10-20 \mathrm{~mm} \mathrm{~h}^{-1}$ (d), and more than $20 \mathrm{~mm} \mathrm{~h}^{-1}$ (e)) and locations: land stations (green), coastal stations (red), semienclosed seas (black), and open seas (blue). The full lines give drop size densities according to the exponential function given in (4) for 1, 3, 6, 12, and $25 \mathrm{~mm} \mathrm{~h}^{-1}$. 
TABLE 1: Number of observations in each category of Figure 5.

\begin{tabular}{|c|c|c|c|c|}
\hline \multirow[b]{2}{*}{ Rain rate $/ \mathrm{mm} \mathrm{h}^{-1}$} & \multicolumn{4}{|c|}{ Number of observations } \\
\hline & Island/Baltic sea & Coast & Land & Open sea \\
\hline $0-2$ & 32888 & 49000 & 14958 & 5499 \\
\hline $2-5$ & 11467 & 40553 & 4196 & 2258 \\
\hline $5-10$ & 2313 & 2865 & 811 & 963 \\
\hline $10-20$ & 990 & 1020 & 234 & 579 \\
\hline$>20$ & 253 & 243 & 148 & 350 \\
\hline
\end{tabular}

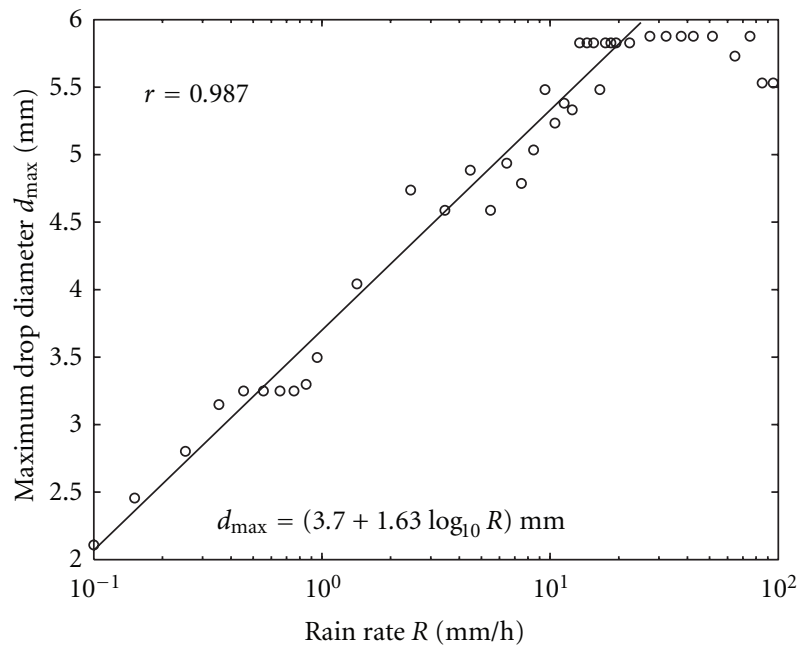

Figure 6: Maximum drop size as a function of rain rate estimated from all available measurements.

maximum diameters at a given rain rate compare well with estimates of Harikumar et al. [22]. The estimate of maximum diameters as a function of rain rates might be limited by the scanned volume of air since the drop size density decreases exponentially with increasing drop diameter (4). Estimates based on this equation, assuming a more conservative value of mean relative wind speed of $5 \mathrm{~ms}^{-1}$, showed that the number of observations for each precipitation interval used to estimate maximum drop sizes (Figure 6) is big enough to detect even larger drops than those given by (5). On average, the totally scanned volume is about 13 times bigger than the volume containing a single drop of maximum drop size at a given rain rate based on a drop size distribution according to (4). Only for a rain rate of $0.1 \mathrm{~mm} \mathrm{~h}^{-1}$, the scanned volume is smaller than necessary.

The drop diameter $D_{50}$, defined as drop diameter in $\mathrm{mm}$ at which half of the rain volume is in smaller drops and half is in larger drops, depends also on rain intensity $R$ in $\mathrm{mm} \mathrm{h}^{-1}$ according to

$$
D_{50}=1.06 \mathrm{~h} \cdot R^{0.22},
$$

which compares well to findings of $\mathrm{McCool}$ et al. [23], who got

$$
D_{50}=1.136 \mathrm{~h} \cdot R^{0.219},
$$

based on measurements in the US Pacific Northwest area.

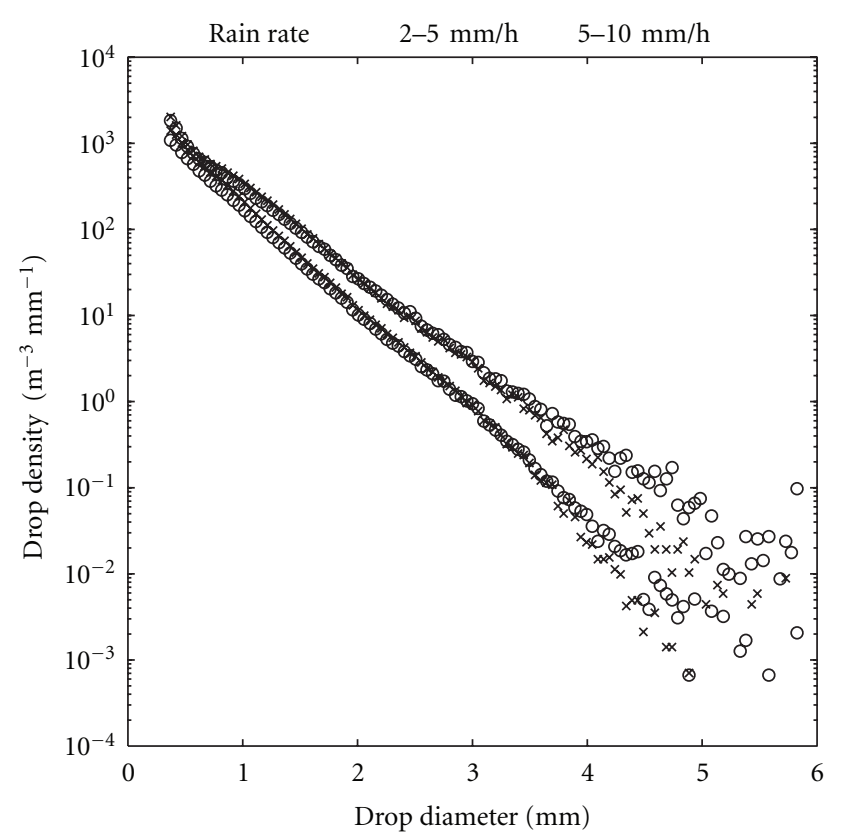

FIGURE 7: Drop size spectra measured on board of R/V Alkor at rain rates of 2 to $5 \mathrm{~mm} / \mathrm{h}$ (lower curves) and 5 to $10 \mathrm{~mm} / \mathrm{h}$, based on 1 minute time series (asterisks) and time series of 10-minutes length (open symbols).

4.5. Drop Size Densities and Length of Time Series. Due to the high temporal and spatial variability of precipitation in combination with a strong dependency of drop size spectra on rain rate, it should be noted that drop size spectra at a given rain rate depend strongly on the length of time series. An example is given for drop size densities derived from measurements on board R/V Alkor, averaged over 10 consecutive minutes with respect to drop size density and rain rate, and compared with original drop size spectra of 1-minute integration time (Figure 7).

A Kolmogoroff Smirnoff test shows that 1 minute and 10-minute drop size spectra are significantly different at the 0.95 level. The reason for this behaviour is that 10 -minute of integration time may comprise certain minutes without any precipitation. Thus, the resulting average precipitation rate is generally lower than the maximum precipitation rate of a single minute within a 10-minute time series, or in other words, the longer the integration time, the bigger are the biggest drops measured at a given precipitation rate. Computing 10-minutes time series by summing up the numbers of drops over 10 consecutive minute, averaging the measured 


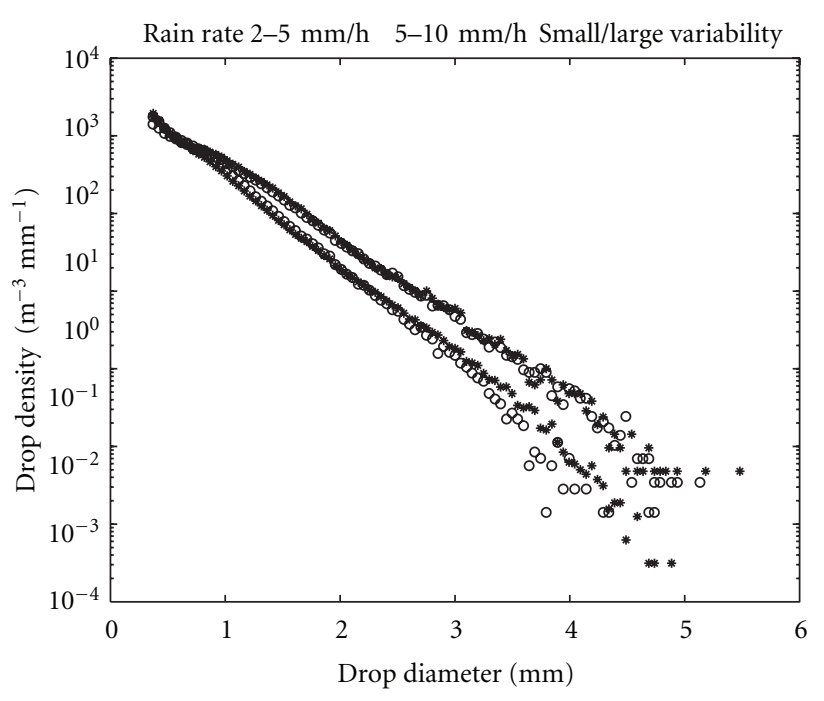

FIGURE 8: Drop size spectra measured on board of R/V Alkor at rain rates of 2 to $5 \mathrm{~mm} / \mathrm{h}$ (lower curves) and 5 to $10 \mathrm{~mm} / \mathrm{h}$, based on 1-minute time series. Open symbols represent precipitation events below; asterisks represent precipitation events with rain rate variabilities above average temporal variability.

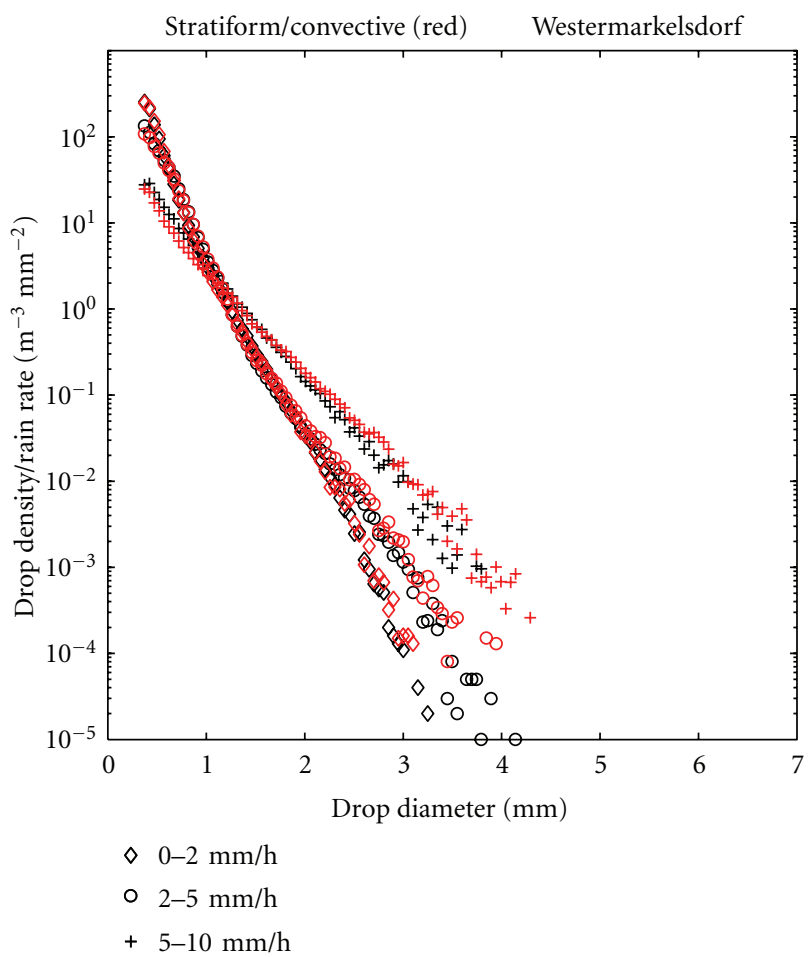

Figure 9: Drop size spectra for stratiform (black symbols) and convective precipitation events (red symbols) as estimated from weather radar based on 1-minute measurements using the optical disdrometer at Westermarkelsdorf.

wind speeds, and applying (2) instead of averaging rain rates and drop size densities came out with the same result.

4.6. Drop Size Densities for Convective and Stratiform Rain. As mentioned above, drop size densities for stratiform and convective precipitation may differ, too. Classifying precipitation in a convective and a stratiform part is a difficult task as it is reflected by the large number of different procedures given in literature. Some possibilities are a vertical velocity based (e.g., Atlas et al. [24]) or weather radar based on (e.g., Bumke et al. [25]) or using a threshold (e.g., Atlas et al. [26]), but the latter is according to Yuter and Houze [27] inconsistent with the methods mentioned before or methods based on spatial/temporal variability. Here, we used two approaches, the temporal variability to separate data of $\mathrm{R} / \mathrm{V}$ ALKOR in stratiform and convective rain and weather radar information to do so for the Westermarkelsdorf data set.

For time series of FS ALKOR, the temporal variance of the rain rate was estimated from running 30-minute time series consisting of 30 single consecutive 1-minute time series to estimate the mean variance as a function of rain rate. Then the time series of FS ALKOR was split in two parts: one part for rain events during periods of rain rates with variability below average and a second part for rain events during periods with above average variability. The first set can be regarded as the stratiform part, the second as the convective part. Figure 8 shows the resulting drop size spectra in comparison.

The result is that there are no differences in drop size spectra for periods of low variability and high variability in rain rates. Thus, one can conclude that there are no differences in drop size spectra for prevailing stratiform and prevailing convective precipitations based on 1-minute time series.

For Westermarkelsdorf, the decision, whether precipitation is stratiform or convective, is based on information of Rostock weather radar [28]. The algorithm bases on an analysis of reflectivity patterns in the horizontal, and vertical. In the horizontal stratiform areas are identified by relatively homogeneous, typically larger areas of low or medium reflectivity, while convective areas show cells of high reflectivity and strong gradients in reflectivity. In the vertical, stratiform areas are characterized by a bright band, thus, showing a well-defined peak in the vertical reflectivity profile. Convective cells do not show such a characteristic maximum, but they reach higher. This has been used to classify the original 1-minute time series (Figure 9) and the averaged 10minute time series (Figure 10) into convective and stratiform subsets. Applying the method of variances as used for RV Alkor data on the Westermarkelsdorf data and comparing the resulting stratiform and convective events with those derived by applying the radar method, the following agreement was achieved: for convective precipitation events, the agreement between both methods is $68 \%$, for stratiform events it is $77 \%$, based on 1-minute time series.

While based on time series of 1-minute length, no significant difference between the stratiform and convective subsets could be detected; significant differences between convective and stratiform drop size spectra do show up based on 10minute time series. The explanation is very simple: during periods of low variability in rain rates, drop size spectra of each 1-minute interval belonging to a 10-minute interval show a similar shape resulting in an average spectrum similar 


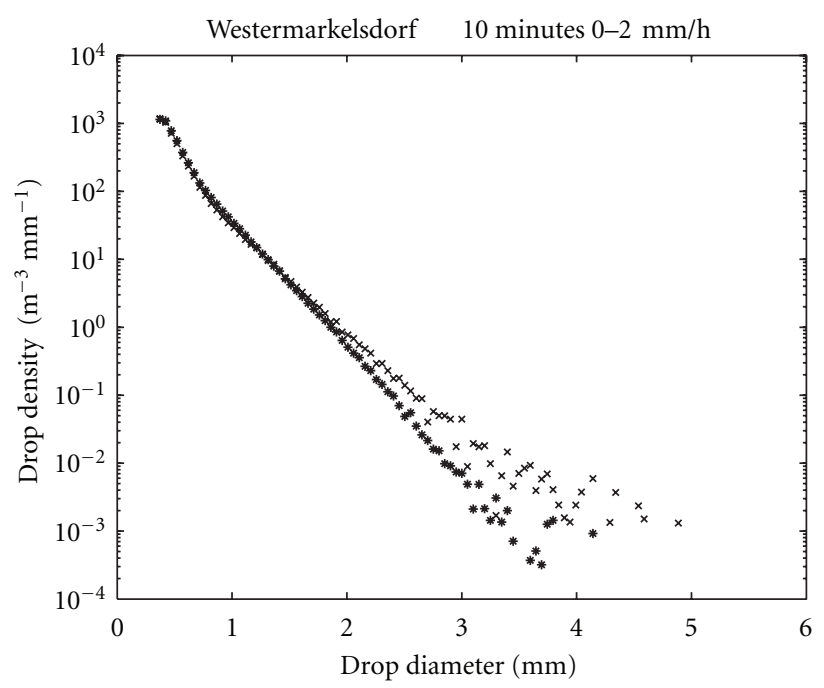

(a)

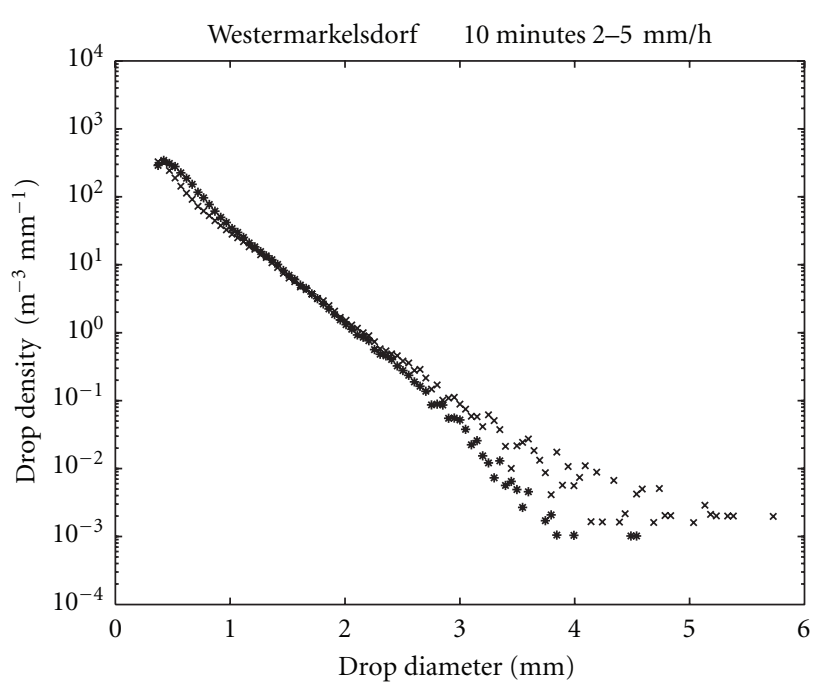

(b)

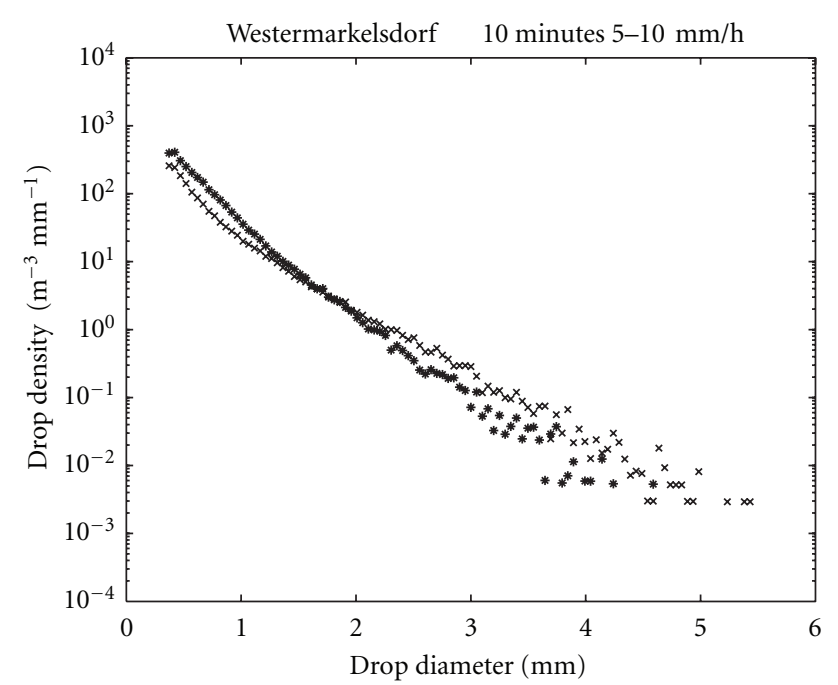

(c)

FIGURE 10: Drop size spectra for stratiform (asterisks) and convective precipitation events (crosses) based on 10-minute measurements using the optical disdrometer at Westermarkelsdorf. The separation in stratiform and convective precipitation was taken from weather radar information.

to those of each single minute. In cases of high variability in rain rates, there are minutes with lower or even zero precipitation and minutes with higher rain rates than in average. Consequently, the resulting spectrum for a 10 minute period contains also bigger drop sizes according to higher rain rates (4). In fact, this averaging effect with respect to precipitation rates leads to stratiform spectra containing smaller drops than convective spectra, as was shown, for example, by Testud et al. [18], and which is a result of the one-sided distribution of precipitation rates, leading always to a smoothing in precipitation rates.

\section{Conclusions}

This study gives an insight into differences of drop size spectra over land and sea. Unlike other studies, no difference could be detected here between drop size densities over land and sea. Main results are that an exponential model fits the measured drop size spectra, where the interception number, the regression coefficient, and the maximum observed drop size depend on the rain rate itself. One might speculate whether gamma distributions derived earlier may be a result of measurement technique. Most of them are derived from Joss-Waldvogel measurements, which are known to underestimate the occurrence of smallest drops (e.g., Williams et al. [29]), or whether this is a result of the limited resolution of smallest drops, here drops of less than $0.4 \mathrm{~mm}$ in diameter, for the optical disdrometer used in this study. In fact, the number of smallest drops is of limited interest for remote sensing of precipitation, since both rain rate and reflectivity are mainly defined by the number of larger drops.

The most important result of this study is that rain drop size densities based on 1-minute time series are identical 
over land and sea and are a function of rain rate only. Some uncertainties remain in which degree condensation nuclei are of prevailing continental or maritime origin at different locations. A certain estimate necessitates simultaneous aerosol measurements. Such an experiment has taken place first in autumn 2010 on a cruise of RV Polarstern from Bremerhaven to Capetown.

A number of recent publications have shown (e.g., Testud et al. [18]) that drop size spectra of convective and stratiform rain do show significant differences. Several approaches have been developed in the past to decide whether precipitation is of stratiform or convective character. Here, we used two of them, temporal variability in rain rates and additional information by weather radar data for the South Western Baltic Sea to separate precipitation events in convective and stratiform subsets. As expected, both methods used for classification show some disagreement leading to an overlap in classification. Results show that no significant differences between drop size densities of stratiform and convective rain for integration times of 1 minute could be found for both methods used for classification. But for integration times of 10 minutes, a typical timescale for convective events, there are indeed significant differences between drop size densities of stratiform and convective rain independent of to the method used for classification. Differences between both methods used for classification indicate clearly that further research is needed. A cloud classification algorithm [30] in combination with simultaneous measurements of an optical disdrometer and a cloud camera gives the possibility to develop a new scheme to separate precipitation in a stratiform and convective part. Such measurements are running now on the main building of the IFM-Geomar in Kiel.

Thus, another main result is that differences in drop size spectra are a result of integration time of measurements as it is expected due to the fact that the maximum drop size is a function of rain rate. It is clear from the results of this study that drop size spectra as well as the resulting ZRrelations depend on the integration time, or equivalently, spatial averaging of precipitation measurements. This has consequences for purposes of remote sensing of precipitation by satellite or weather radar. Spatial/temporal variability seems to be an important and necessary information, for example, to get reliable numbers of the areal relation between reflectivity and rain rate for areas of the radar volume or a satellite's footprint.

In this sense, there are indeed differences between stratiform and convective precipitation, which has typical time scales of 10 minutes and more although our results based on 1-minute measurements give an opposite picture. Thus, future research should focus on differences in the small-scale spatial variability of precipitation patterns to improve remote sensing of precipitation.

\section{Acknowledgments}

The authors would like to thank the masters and crews of all ships and the staff of all measurement sites for their support. Furthermore, they would like to thank everybody, who performed the measurements, especially Lutz Hasse, Martin Großklaus, Marco Clemens, and Klaus Uhlig. Parts of this study were funded by the Deutsche Forschungsgemeinschaft (Niederschlagsmessung auf See, BALTEX, COPS), the European Union (Joule and PEP), and the German Ministry of Research (DEKLIM).

\section{References}

[1] J. S. Marshall and W. K. M. Palmer, "The distribution of rain drops with size," Journal of Meteorology, vol. 5, pp. 165-166, 1948.

[2] C. W. Ulbrich and D. Atlas, "Microphysics of raindrop size spectra: tropical continental and maritime storms," Journal of Applied Meteorology and Climatology, vol. 46, no. 11, pp. 17771791, 2007.

[3] M. Sekine, S. Ishii, S. I. Hwang, and S. Sayama, "Weibull raindrop-size distribution and its application to rain attenuation from $30 \mathrm{GHz}$ to $1000 \mathrm{GHz}$," International Journal of Infrared and Millimeter Waves, vol. 28, no. 5, pp. 383-392, 2007.

[4] M. Großklaus, Niederschlagsmessung auf dem Ozean von fahrenden Schiffen, vol. 278, Berichte aus dem Institut für Meereskunde an der Christian-Albrechts-Universität Kiel, Institut für Meereskunde, Kiel, Germany, 1996.

[5] R. Uijlenhoet, M. Steiner, and J. A. Smith, "Variability of raindrop size distributions in a squall line and implications for radar rainfall estimation," Journal of Hydrometeorology, vol. 4, no. 1, pp. 43-61, 2003.

[6] M. Großklaus, K. Uhlig, and L. Hasse, "An optical disdrometer for use in high wind speeds," Journal of Atmospheric and Oceanic Technology, vol. 15, no. 4, pp. 1051-1059, 1998.

[7] D. Atlas, R. Srivastava, and R. Sekhon, "Doppler radar characteristics of precipitation at vertical incidence," Reviews of Geophysics, vol. 11, no. 1, pp. 1-35, 1973.

[8] M. Clemens, Machbarkeitsstudie zur räumlichen Niederschlagsanalyse aus Schiffsmessungen über der Ostsee, Ph.D. thesis, Christian-Albrechts-Universität, Kiel, Germany, 2002.

[9] A. Tokay, A. Kruger, and W. F. Krajewski, "Comparison of drop size distribution measurements by impact and optical disdrometers," Journal of Applied Meteorology, vol. 40, no. 11, pp. 2083-2097, 2001.

[10] B. E. Sheppard and P. I. Joe, "Comparison of raindrop size distribution measurements by a Joss- Waldvogel disdrometer, a PMS 2DG spectrometer, and a POSS Doppler radar," Journal of Atmospheric and Oceanic Technology, vol. 11, no. 4, pp. 874$887,1994$.

[11] J. Joss and A. Waldvogel, "Ein Spektrograph für Niederschlagstropfen mit automatischer Auswertung," Pure and Applied Geophysics, vol. 68, no. 1, pp. 240-246, 1967.

[12] G. Peters, B. Fischer, and T. Andersson, "Rain observations with a vertically looking Micro Rain Radar (MRR)," Boreal Environment Research, vol. 7, no. 4, pp. 353-362, 2002.

[13] H. Sauvageot and J. P. Lacaux, "The shape of averaged drop size distributions," Journal of the Atmospheric Sciences, vol. 52, no. 8, pp. 1070-1083, 1995.

[14] L. Hasse, M. Großklaus, K. Uhlig, and P. Timm, "A ship rain gauge for use in high wind speeds," Journal of Atmospheric and Oceanic Technology, vol. 15, no. 2, pp. 380-386, 1998.

[15] B. Sveruk, "Correction of precipitation measurementssummary report," in Correction of Precipitation Measurements, B. Sveruk, Ed., vol. 23, pp. 13-23, Züricher Geographische Schriften, 1986. 
[16] A. Stohl, "Computation, accuracy and applications of trajectories-a review and bibliography," Atmospheric Environment, vol. 32, no. 6, pp. 947-966, 1998.

[17] A. Engström and L. Magnusson, "Estimating trajectory uncertainties due to flow dependent errors in the atmospheric analysis," Atmospheric Chemistry and Physics, vol. 9, no. 22, pp. 8857-8867, 2009.

[18] J. Testud, S. Oury, R. A. Black, P. Amayenc, and X. Dou, "The concept of "normalized" distribution to describe raindrop spectra: a tool for cloud physics and cloud remote sensing," Journal of Applied Meteorology, vol. 40, no. 6, pp. 1118-1140, 2001.

[19] I. G. Doelling, J. Joss, and J. Riedl, "Systematic variations of Z-R-relationships from drop size distributions measured in northern Germany during seven years," Atmospheric Research, vol. 47-48, pp. 635-649, 1998.

[20] C. Mallet and L. Barthes, "Estimation of gamma raindrop size distribution parameters: statistical fluctuations and estimation errors," Journal of Atmospheric and Oceanic Technology, vol. 26, no. 8, pp. 1572-1584, 2009.

[21] R. C. Srivastava, "Size distribution of raindrops generated by their breakup and coalescence," Journal of the Atmospheric Sciences, vol. 28, no. 3, pp. 410-415, 1971.

[22] R. Harikumar, S. Sampath, and V. S. Kumar, "Variation of rain drop size distribution with rain rate at a few coastal and high altitude stations in southern peninsular India," Advances in Space Research, vol. 45, no. 4, pp. 576-586, 2010.

[23] D. K. McCool, J. D. Williams, and J. R. Morse, "Raindrop characteristics in the Pacific Northwest," Tech. Rep. 097441, 2009, ASABE Paper.

[24] D. Atlas, C. W. Ulbrich, F. D. Marks Jr. et al., "Partitioning tropical oceanic convective and stratiform rains by draft strength," Journal of Geophysical Research D, vol. 105, no. 2, pp. 2259-2267, 2000.

[25] K. Bumke, M. Clemens, H. Graßl et al., "More accurate areal precipitation over land and sea: APOLAS Abschlussbericht," Tech. Rep. MPI-M-2006-0012, Max-Planck-Institut f. Meteorologie, Hamburg, Germany, 2006, Reports on Earth System Science 22.

[26] D. Atlas, C. W. Ulbrich, and F. D. Marks Jr., "Reply," Journal of Geophysical Research, vol. 107, no. 1, p. 4006, 2002.

[27] S. E. Yuter and R. A. Houze Jr., "Comment on 'Partitioning tropical oceanic convective and stratiform rains by draft strength' by David Atlas et al," Journal of Geophysical Research, vol. 107, no. 1, 2002.

[28] K. Bumke, B. Fischer, G. Peters et al., "APOLAS: more accurate areal precipitation over land and sea," BALTEX Newsletter, vol. 8, pp. 8-10, 2005.

[29] C. R. Williams, A. Kruger, K. S. Gage et al., "Comparison of simultaneous rain drop size distributions estimated from two surface disdrometers and a UHF profiler," Geophysical Research Letters, vol. 27, no. 12, pp. 1763-1766, 2000.

[30] A. Heinle, A. Macke, and A. Srivastav, "Automatic cloud classification of whole sky images," Atmospheric Measurement Techniques, vol. 3, pp. 557-567, 2010. 

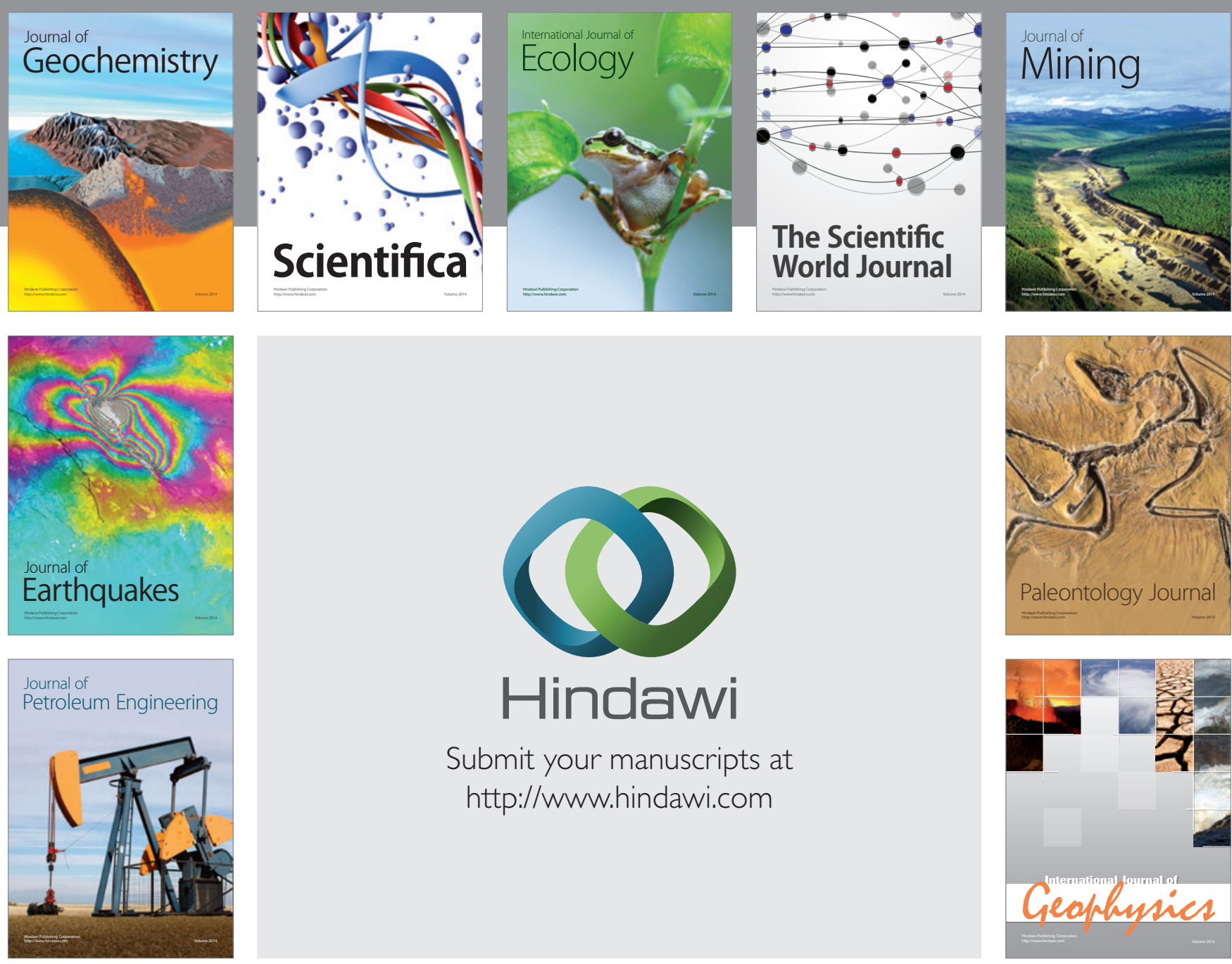

Submit your manuscripts at

http://www.hindawi.com
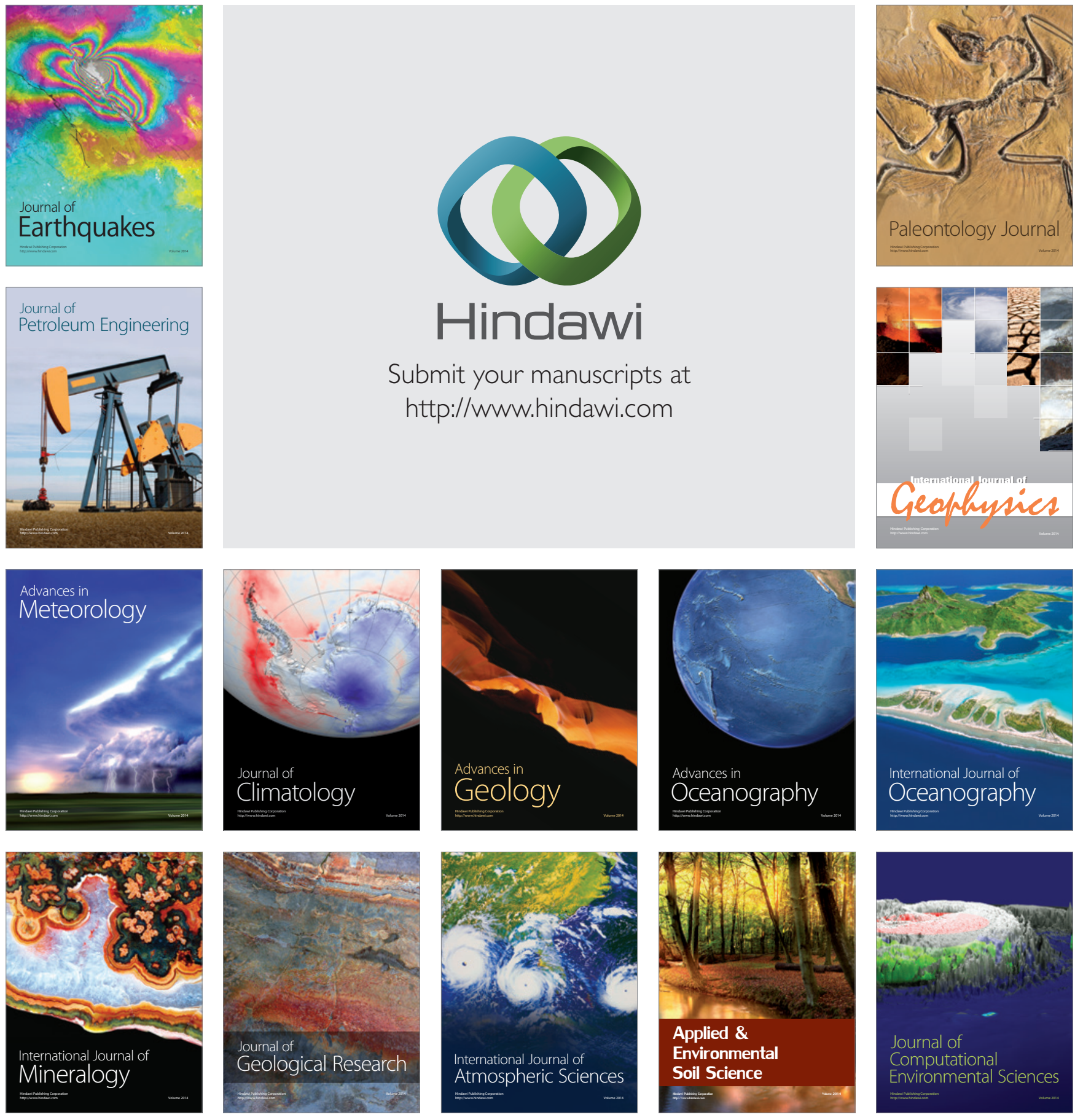